\title{
Site- and Motion-Dependent Parametric Uncertainty of Site-Response Analyses in Earthquake Simulations
}

\author{
by W. Li and D. Assimaki
}

\begin{abstract}
We investigate the propagation of uncertainty in site-response analyses from the soil model parameters to the ground surface motion at three downhole array sites in the Los Angeles (LA) Basin. For this purpose, we develop realistic stochastic models of elastic and nonlinear dynamic soil properties using extensive site-specific and generic geotechnical data on the variability of soil properties. We also generate synthetic ground motions using a finite source dynamic rupture model over a wide range of magnitudes and distances and use this statistically significant number of ground motions in the analysis. For each of the three sites, we evaluate the effects of soil parameter uncertainty as a function of the seismic input intensity and frequency content. We show that the frequency range, where the ground-motion variability due to soil parameter uncertainty is maximized, is a function of both the site and the seismogram characteristics. We compare our results with previously published studies and show that different soil models, statistical descriptions of soil parameters, or groundmotion scenarios may yield substantial differences in the estimated site-response scatter. We conclude that the effects of nonlinear soil property uncertainties on the ground-motion variability strongly depend on the seismic motion intensity, and this dependency is more pronounced for soft soil profiles. By contrast, the effects of velocity profile uncertainties are less intensity dependent and more sensitive to the velocity impedance in the near surface that governs the maximum site amplification.
\end{abstract}

\section{Introduction}

Nonlinear site effects play a very important role in the development of successful seismic hazard assessment and mitigation strategies. However, the limited number of in situ geotechnical investigation data, the effects of sample disturbance and scaling associated with laboratory tests, and the natural heterogeneity of soil profiles are significant sources of uncertainty in nonlinear site-response predictions. In addition, simulations of nonlinear effects are strongly affected by uncertainties in the intensity and frequency content of incident ground motion, the constitutive soil model used in the analysis, and the surface and subsurface geometry at the site (2D and 3D effects).

The uncertainties associated with the description of soil parameters and the spatial variability of near-surface profiles have been long acknowledged, and their effects on the ground and structural response have been demonstrated in the past by stochastic finite-element analyses and uncertainty propagation procedures such as Monte Carlo simulations (MCSs). Typical examples include the work of Ohtomo and Shinozuka (1990), Fenton (1990), Ural (1995), Popescu (1995), and Popescu et al. (1995) on the effects of spatial variability on soil liquefaction; Griffiths and Fenton (1993), Dham and Ghanem (1995), and Fenton and Griffiths (1996) on seepage through spatially random soils; Paice et al. (1996) on settlements; and the work of Nobahar and Popescu (2000) and Fenton and Griffith (2001) on shallow foundations.

In this article, we examine the effects of soil parameter uncertainty on the prediction of strong ground motion. Several studies have been published on this topic in the past: Hwang and Lee (1991) studied the response of two hypothetical profiles of sand and clay subjected to an $M_{\mathrm{w}} 7.5$ scenario earthquake in the New Madrid Seismic Zone. Tian and Jie (1992), Wu and Han (1992), and Suzuki and Asano (1992) investigated the effects of 1D spatial variability of shear-wave velocity $\left(V_{S}\right)$, density $(\rho)$, damping $(\xi)$, and soil layer thickness $(h)$ using each randomized realizations of one base layered structure; and Field and Jacob (1993) evaluated the weak-motion response of two base profiles in the Turkey Flat strong-motion array. Roblee et al. (1996) used a stochastic finite-fault model to study the ground response variability due to uncertainties in the source, path, and site conditions and showed that the controlling parameters in ground-motion predictions are the soil profile, ground-motion amplitude, and frequency range of interest. They showed that for soil sites subjected to moderate-to-strong ground motion, site effects dominated the response variability for periods up 
to several seconds and estimated the effects of soil parameter uncertainty on the response of a stiff site subjected to an $M_{\mathrm{w}} 7$ event at distance $R=10 \mathrm{~km}$ using equivalent linear soil response analysis; for this site and ground motion, the maximum response variability was observed at $T=0.2 \mathrm{sec}$.

Additional work includes the published results by Rahman and Yeh (1999) for one base profile with ground motion being simulated as a stationary random process with fixed frequency content; Wang and Hao (2002), who included the effects of groundwater level on the ground surface response variability; Nour et al. (2003), who investigated the effects of correlation distance of the soil $V_{S}, \xi$, and Poisson ratio $(V)$ for a 2D configuration; Assimaki et al. (2003) and Bazzurro and Cornell (2004), who investigated the effective stress transient nonlinear response of cohesive and cohesionless sites subjected to multiple recorded ground motions; Andrade and Borja (2006), who compared the ground response variability due to soil parameter uncertainty predicted at two sites by means of the equivalent linear (Idriss and Sun, 1992) and time-domain nonlinear (Borja et al., 2000) models; and Stewart and Kwok (2008) and Kwok et al. (2008), who evaluated the effects of soil parameter uncertainty on the response of La Cienega and Turkey Flat vertical array profiles to strong ground motion events using the nonlinear site-response computer code DEEPSOIL (Hashash et al., 2008) as part of a study that looked at several site-response codes and their prediction variability.

The most common limitations of these studies are associated with (1) the statistical models used to describe the variability of soil properties, (2) the small number of ground motions used in the analyses, (3) the use of simplified pulses as opposed to broadband seismograms, (4) the lack of design level records in the analyses to illustrate the effects of soil parameter uncertainty for very large strains, and (5) the implementation of approximate methods instead of realistic nonlinear soil models in the site-response simulations. More specifically, Hwang and Lee (1991), Tian and Jie (1992), Assimaki et al. (2003), Andrade and Borja (2006), and Stewart and Kwok (2008) used a very limited number of ground motions; Wu and Han (1992), Rahman and Yeh (1999), and Nour et al. (2003) studied simplified pulses instead of true seismic excitations; Suzuki and Asano (1992) and Field and Jacob (1993) limited their study to weak ground-motion recordings. In the majority of these studies, results illustrated the effects of uncertainty in the low-strain (visco-elastic) soil properties (Suzuki and Asano, 1992; Tian and Jie, 1992; Wu and Han, 1992; Filed and Jacob, 1993; Rahman and Yeh, 1999; Assimaki, 2003; Nour et al., 2003). Also, the variability statistics of visco-elastic and nonlinear soil parameters in these studies are by and large described by simplified probability distribution functions and correlation structures, while typical near-surface geologic formations tend to exert more complex spatial variability characteristics.

In this article, we conduct a comprehensive study on the effects of soil parameter uncertainty on site-response analyses addressing several of the limitations described previously. More specifically, (1) we use extensive geotechnical data on the variability statistics of soils at three downhole array sites in the Los Angeles (LA) Basin (Darendeli, 2001; Anderson, 2003; Toro, 1993) and develop realistic stochastic fields of elastic and nonlinear dynamic soil properties, (2) we generate synthetic ground motions by means of a finite source dynamic rupture model (Liu et al., 2006) over a wide range of magnitudes and distances to obtain a statistically significant number of ground motions for the analysis, and (3) we simulate the large-strain response of soils by means of a hysteretic soil model validated by comparison with downhole seismogram recordings (Assimaki et al., 2008, 2010). For each of the three sites, we evaluate the effects of soil parameter uncertainty as a function of the seismic input intensity and frequency content. We show that the frequency range, where site-response variability due to soil parameter uncertainty is maximized, is a function of both the site and the ground motion. We compare our results with previously published data and show that different soil models, soil property variability statistics models, or ground-motion scenarios may yield significant differences in the estimated site-response scatter.

\section{Site Conditions and Ground-Motion Synthetics}

This work is based on a previous study by the authors (Assimaki et al., 2008), who evaluated the soil modeling variability in site-response predictions at three downhole array sites in Southern California using approximate and rigorous nonlinear site-response models and synthetic ground motions. The position coordinates, operating agencies, depth of downhole instruments, and geological description of the sites are given in Table 1. Downhole and suspension logging

Table 1

Strong-Motion Geotechnical Array Stations in the Los Angeles Basin

\begin{tabular}{lcccrlc}
\hline \multicolumn{1}{c}{ Station Name } & Latitude & Longitude & Agency $^{*}$ & Station Depth ${ }^{\ddagger}(\mathrm{m})$ & \multicolumn{1}{c}{ Geology } & NEHRP $^{\ddagger}$ Site Class \\
\hline Obregon Park (CE.K400) & 34.037 & -118.178 & SCEC & 0,70 & $\mathrm{Q}^{\S}$ & $\mathrm{C}$ \\
Los Angeles_La Cienega Geotechnical Array & 34.036 & -118.378 & CSIP & $0,18,100,252$ & Deep alluvium & D \\
El Centro-Hwy8/Meloland Overpass & 32.773 & -115.447 & CSIP & $0,30,100,252$ & Deep alluvium & E \\
\hline
\end{tabular}

*CSIP, California Strong Motion Instrumentation Program; SCEC, Southern California Earthquake Center.

Location of downhole receivers.

${ }^{\ddagger}$ NEHRP, National Earthquake Hazards Reduction Program.

${ }^{\S} \mathrm{Q}$, Quaternary. 
measurements and laboratory resonant column modulus reduction and damping curves (Anderson, 2003) were available at these locations. Attenuation $(Q)$ and density $(\rho)$ profiles were estimated by inversion of low-amplitude seismogram recordings using the waveform inversion algorithm by Assimaki et al. (2006). The compiled shear-wave velocity $\left(V_{S}\right)$, attenuation $(Q=1 / 2 \xi$, where $\xi$ is the material damping), and density profiles $(\rho)$ are shown in Figure 1 and are used as base profiles of the random soil property fields in this study.

Because strong ground motion recordings at these stations were scarce, Assimaki et al. (2008) developed a statistically significant dataset of seismic input motions using synthetic records. For this purpose, they used 1D crustal compressional velocity $\left(V_{P}\right)$, shear velocity $\left(V_{S}\right)$, and density
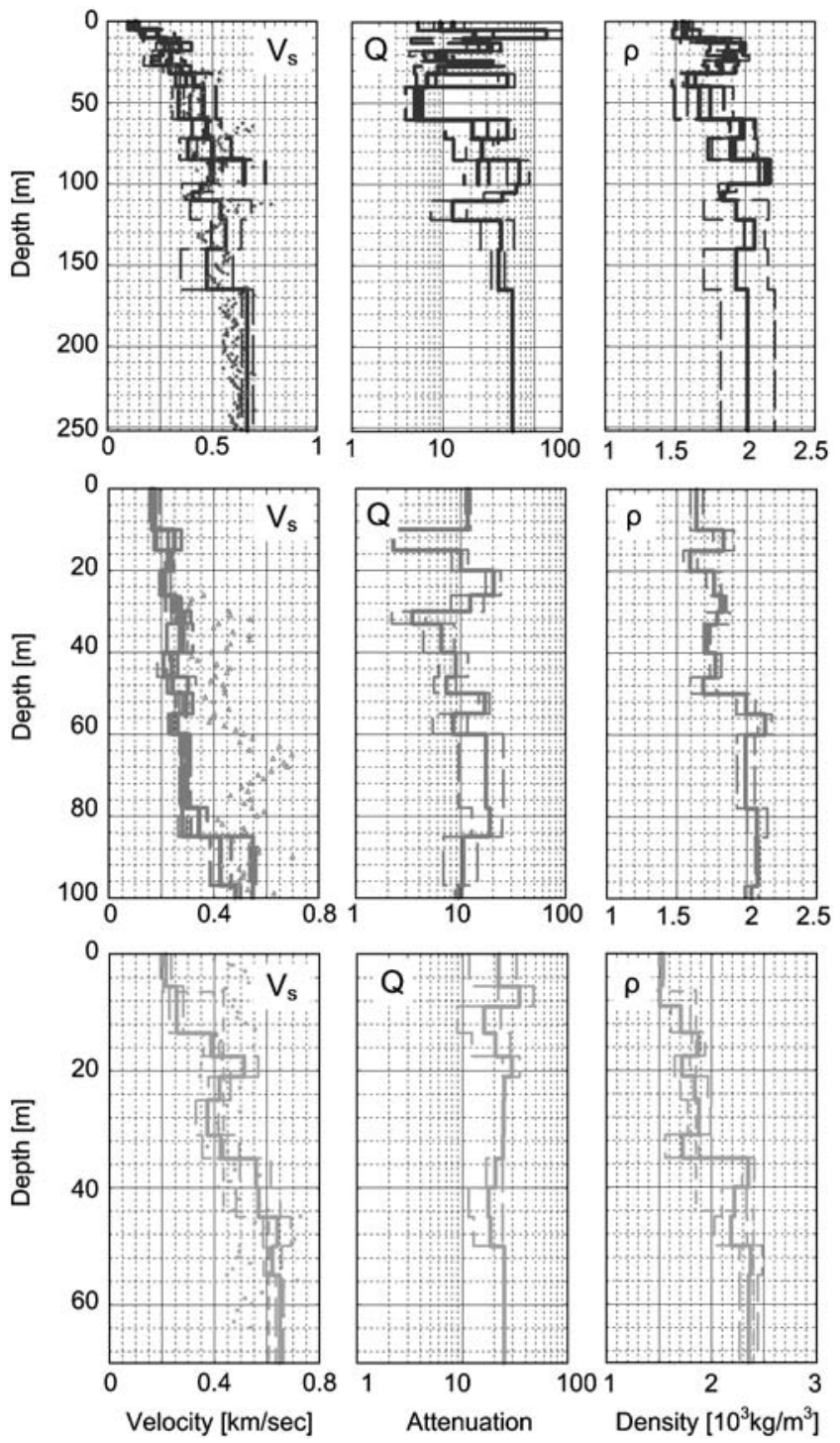

Figure 1. Shear-wave velocity $\left(V_{S}\right)$, attenuation $(Q)$, and density $(\rho)$ profiles evaluated by means of downhole array seismogram inversion at the three Strong Motion Geotechnical Array (SMGA) stations: La Cienega (top); Meloland (middle); and Obregon Park (bottom). models $(\rho)$ from the 3D Southern California Community Velocity Model IV (SCEC CVM IV; see the Data and Resources section) and the hybrid low-/high-frequency dynamic rupture source model by Liu et al. (2006). They simulated multiple strike-slip fault rupture scenarios over a square grid of surface stations for medium to large magnitude events $\left(M_{\mathrm{w}} 3.5-7.5\right)$ at distances $R=2.0-75 \mathrm{~km}$. These ground motions are also used in the following analyses.

Finally, Assimaki et al. (2008) conducted site-response simulations at the three sites for the limited number of recorded ground motions and the synthetic seismograms using multiple soil models. They evaluated the deviation of ground surface predictions from the observed time histories and identified the monotonic constitutive law by Matasovic and Mladen (1995) coupled with a modified hysteretic formulation of the model proposed by Muravskii (2005) as the hysteretic soil model that yielded the minimum average error. This model was also implemented the nonlinear site-response analyses described subsequently.

\section{Statistical Description of Soil Parameter Uncertainty}

We next describe the geotechnical site-specific and generic data on the variability of soil parameters used in this study and the idealized probability distribution functions we implemented in the analyses to approximate the empirical data.

The shear-wave velocity $\left(V_{S}\right)$ and the shear modulus reduction $\left(G / G_{\max }\right)$ and material damping $(\xi)$ as a function of cyclic shear strain amplitude $\left(\gamma_{\max }\right)$ were selected as free soil model parameters in the uncertainty propagation estimation. The soil shear strength $\left(\tau_{\max }\right)$ was not considered because the database of synthetic records contained very few input motions that could cause failure in the soil; for the medium to high strain region investigated here, the effects of $\tau_{\max }$ variability could be neglected with no loss of accuracy in the results. According to Phoon and Kulhawy (1999), typical sources of uncertainty in the description of these parameters are (1) the inherent heterogeneity of soils, (2) the scarcity of geotechnical information on the soil nonlinear response, and (3) laboratory measurement errors related to sample disturbance, sample size, and implementation of empirical formulas to transform index to design soil properties. Separation of the sources of uncertainty is rarely feasible, and a single probability distribution function is typically used for each parameter, without explicit consideration of the individual contributing factors (Toro, 1993; Darendeli, 2001). The variability statistics of the soil parameters investigated in this study are described next.

\section{Low-Strain Shear-Wave Velocity $\left(V_{S}\right)$}

We adopted the statistical model by Toro (1993) to describe the uncertainties of low-strain soil shear-wave velocity $\left(V_{S}\right)$. This probabilistic model was developed using data from generic soil profiles in the EPRI (1993) database, and the 
model describes the intralayer (i.e., the probability distribution) and the interlayer (i.e., the spatial variability statistics) shear-wave velocity $\left(V_{S}\right)$ statistical properties, as well as the layer thickness randomness in typical soils. Layered profiles tend to be more variable in the near surface (i.e., require a finer discretization), and Toro's (1993) model accounts for this characteristic by implementing a nonhomogeneous Poisson process with a depth-dependent rate to describe soil layering. A modified power-law model is selected to characterize the depth-dependent rate of layer boundaries, whose coefficients need to be estimated from the available geotechnical data by means of the method of maximum likelihood (Benjamin and Cornell, 1971). Based on the ensemble of data in the EPRI (1993) database, the rate $(\lambda)$ was estimated as

$$
\lambda(h)=1.98(h+10.86)^{-0.89},
$$

where $\lambda$ is the rate of layer boundaries $\left(\mathrm{ft}^{-1}\right)$, and $h$ denotes depth in feet.

In addition to the probabilistic description of the soil layer thicknesses, we use Toro's (1993) velocity model to idealize the variability of $V_{S}$ within each layer and its correlation with adjacent layers. More specifically, Toro (1993) studied the probability distribution of $\ln \left(V_{S}\right)$ using the cumulative distribution of standardized variables shown in equation (2) for generic soil profiles (Fig. 2):

$$
Z_{i}=\frac{\ln \left(V_{i}\right)-\ln \left(V_{\text {median }, i}\right)}{\sigma_{\ln V}},
$$

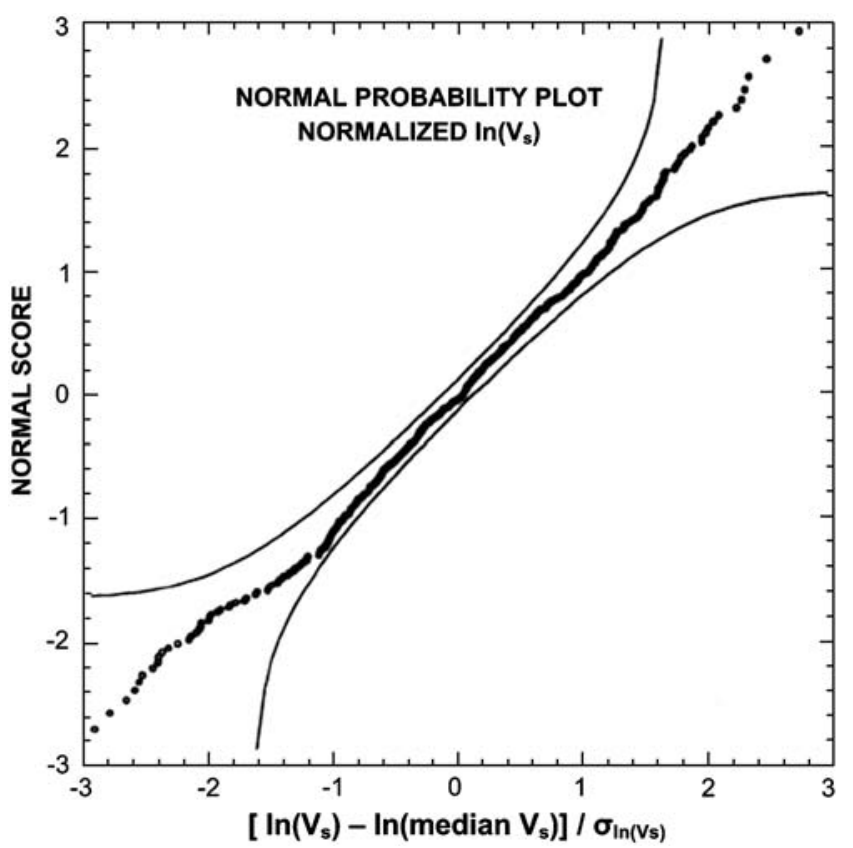

Figure 2. Lognormal probability plot evaluated using the ensemble of data from the EPRI shear-wave velocity $\left(V_{S}\right)$ database. Smooth curves correspond to the $10 \%$ Kolmogorov-Smirnov bounds of the probability distribution. A lognormal distribution was implemented in this study as well to describe the $V_{S}$ distribution in each layer of the profiles studied (modified from Toro, 1993). where $V_{i}$ is the velocity at the midpoint of layer $i, V_{\text {median }, i}$ is the median velocity of the same layer, and $\sigma_{\ln V}$ is the standard deviation of $\ln \left(V_{S}\right)$. Note that the thin solid lines in Figure 2 represent the 10\% Kolmogorov-Smirnov bounds (Benjamin and Cornell, 1971) and the observed $\ln \left(V_{S}\right)$ values plot on a nearly straight line within the bounds, which indicates that $V_{S}$ variability for typical soil formations can be described by a lognormal distribution. Following Toro (1993), we characterized the lognormal distribution of $V_{S}$ and the $V_{S}$ layer-to-layer correlation at the three sites using a first-order autoregressive model, that is,

$$
Z_{1}=\varepsilon_{1}, \quad Z_{i}=\rho Z_{i-1}+\sqrt{1-\rho^{2}} \varepsilon_{i} \quad(i<1),
$$

where $\rho$ is the serial autocorrelation coefficient of $Z$, and $\varepsilon_{i}$ are independent normal random variables with zero mean and unit standard deviation. Equation (3), the parameters $\rho$ and $\sigma_{\ln V}$, and the median $V_{S}$ profile define completely the probabilistic velocity model. Toro (1993) estimated the parameters $\rho$ and $\sigma_{\ln V}$ using data from generic soil profiles via linear regression as $\rho=0.577$ and $\sigma_{\ln V}=0.39$ (corresponding to a velocity coefficient of variation $\mathrm{COV}=41 \%$ ), and these values were also adopted in this study. Note that if more detailed geotechnical data were available at the site, the parameters $\rho$ and $\sigma_{\ln V}$ of the lognormal distribution would have been calibrated based on the site-specific information, and the $V_{S}$ stochastic model would have been characterized by a lower COV. The generic site probabilistic model adopted here yields a wider range of ground surface response, namely, an upper bound description of the ground-motion variability due to uncertainty in the soil velocity profile.

The autocorrelation function used in this work is plotted in Figure 3, and the strong correlation between $V_{S}$ values of adjacent layers described by $\rho=0.577$ is later shown to

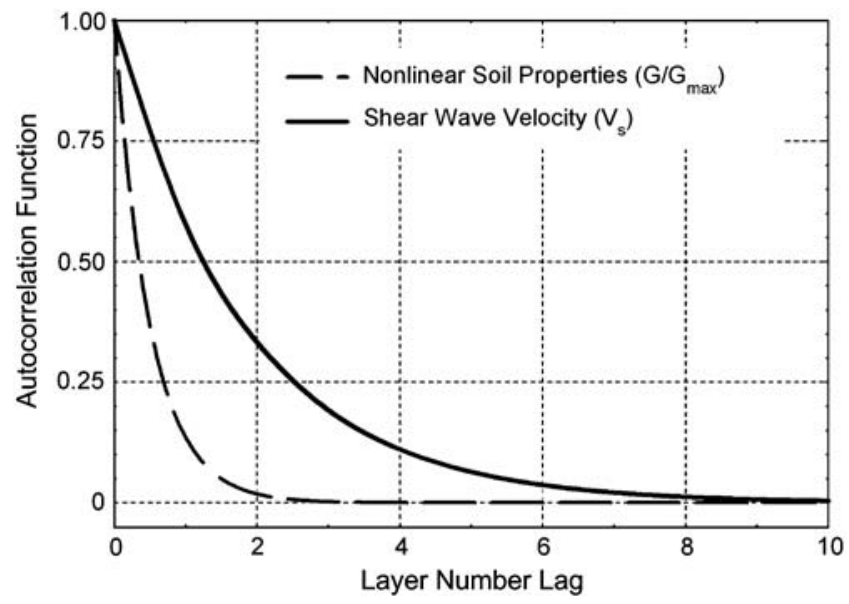

Figure 3. Autocorrelation function describing the layer-to-layer correlation of shear-wave velocity $\left(V_{S}\right)$ and nonlinear dynamic soil properties in this study. Note that the latter was evaluated for the spatial distribution of $G / G_{\max }$ at $0.03 \%$ strain, while perfect correlation was assumed for the remaining of the $G / G_{\max }$ data points and associated material damping $(\xi)$ values (see also Fig. 6). 
favor the convergence rate of MCSs. Using Toro's (1993) probabilistic velocity model, random realizations of the $V_{S}$ stochastic fields were next generated using a two standard deviation ( 2 std) truncation of the lognormal distribution to eliminate potential outliers. Realizations of the $V_{S}$ random profile at the La Cienega downhole array site are shown in Figure 4, where the thick black line corresponds to the median profile at the site (Assimaki et al., 2008), and the thin gray lines correspond to 50 randomized $V_{S}$ profiles.

\section{Modulus Reduction $\left(G / G_{\max }\right)$ and Material Damping $(\xi)$}

Darendeli (2001) studied the covariance structure of modulus reduction $\left(G / G_{\max }\right)$ and material damping $(\xi)$ curves of soils using a first-order second-moment (FOSM) Bayesian method on 110 soil samples from Northern California, Southern California, South Carolina, and Taiwan

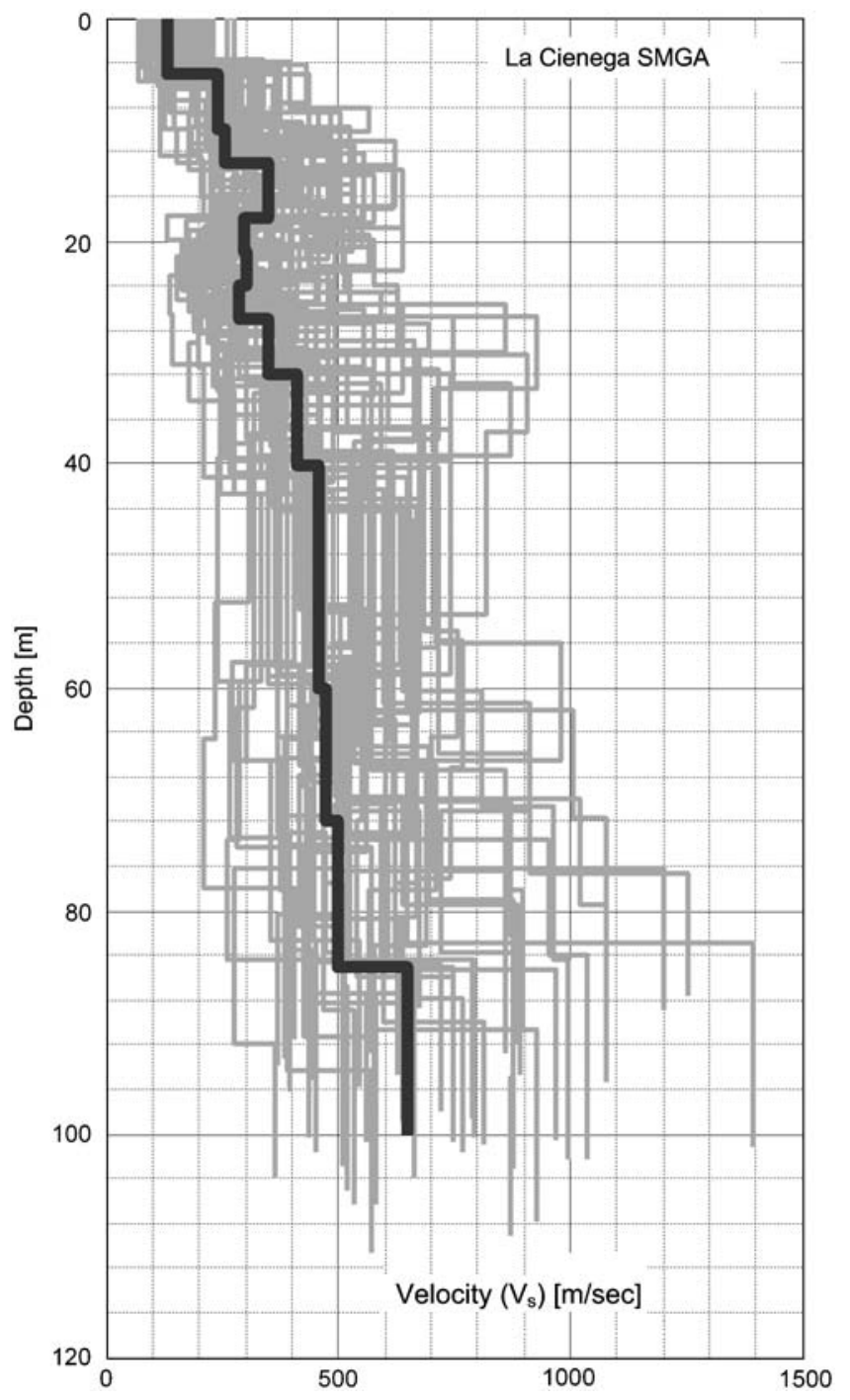

Figure 4. Sample realizations of shear-wave velocity $\left(V_{S}\right)$ profile at the La Cienega SMGA (black line corresponds to the base profile, and gray lines to 50 realizations of the random field). (see also Kottke and Rathje, 2009, who implemented Darendeli's statistical data to site response analyses using random vibration theory). In this work, we use the probabilistic model proposed by Darendeli (2001) to describe the nonlinear soil parameter uncertainty, according to which the straindependent standard deviation of modulus reduction curves $\left(G / G_{\max }\right)$ for generic soil conditions can be represented by the following expression:

$$
\sigma_{G / G_{\max }}=\exp \left(\varphi_{13}\right)+\sqrt{\frac{0.25}{\exp \left(\varphi_{14}\right)}-\frac{\left(G / G_{\max }-0.5\right)^{2}}{\exp \left(\varphi_{14}\right)}}
$$

where $\sigma_{G / G_{\max }}$ is the data standard deviation at a given strain level, $G / G_{\max }$ is the corresponding median value of modulus reduction, and $\varphi_{13}$ and $\varphi_{14}$ are model parameters that depend on the soil type. Darendeli (2001) also evaluated the straindependent standard deviation of material damping $(\xi)$ curves for generic soils as follows:

$$
\sigma_{\xi}=\exp \left(\varphi_{15}\right)+\exp \left(\varphi_{16}\right) \sqrt{\xi}
$$

where $\sigma_{\xi}$ is the data standard deviation at a given strain level, $\xi$ is the corresponding median material damping ratio, and $\varphi_{15}$ and $\varphi_{16}$ are model parameters that also depend on the soil type. The mean values of the model parameters $\varphi_{13}$, $\varphi_{14}, \varphi_{15}$, and $\varphi_{16}$ for generic clays were estimated by Darendeli (2001) as 4.0, -5.0, -0.725 , and 7.67, correspondingly, and these values were also adopted here. The resulting strain-dependent standard deviation of dynamic soil properties for generic sedimentary sites is shown in Figure 5.

To complete the statistical description of nonlinear soil parameters in this study, we introduced three additional assumptions to allow realistic realizations of $G / G_{\max }$ and $\xi$ curves for layered media. These assumptions are based on the statistical analysis of dynamic soil properties for generic soil profiles conducted by Toro (1993) and the limited sitespecific data collected at the downhole array site La Cienega in the LA Basin by Anderson (2003). More specifically, we assume

1. Perfect correlation between $G / G_{\max }$ values at different strain levels.

2. Perfect correlation between $G / G_{\max }$ and material damping $(\xi)$ at each strain level. Figure 6 shows the regression analysis we conducted on data from the EPRI (1993) generic soil database at multiple strain levels, which showed very strong correlation between $G / G_{\max }$ and material damping $(\xi)$. We repeated the linear regression analysis for the ensemble of geotechnical data available, both sitespecific and generic, and plotted the regression slope (referred to as coefficient of proportionality) in Figure 7. We observed consistency between the statistical properties of the various datasets, with the coefficients evaluated for sands using data by Darendeli (2001) and Toro (1993) nearly coinciding at strain amplitudes above $0.05 \%$. In this study, we adopt the proportionality coefficients 

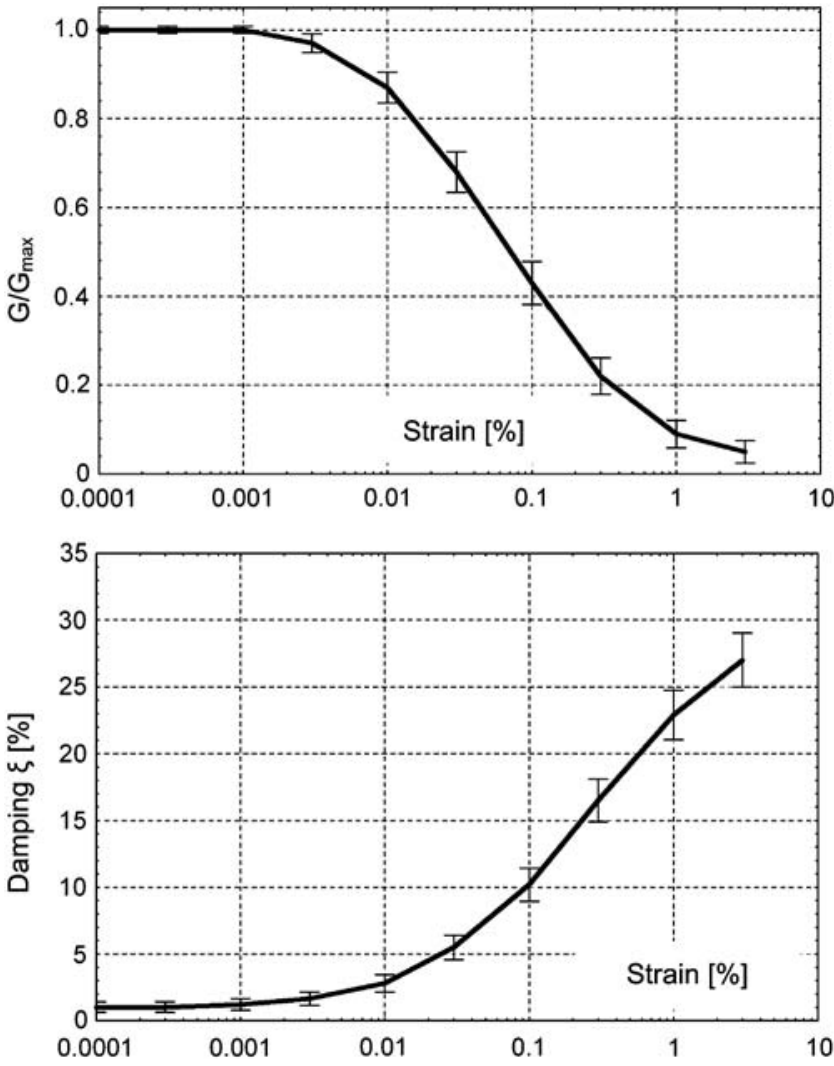

Figure 5. Strain-dependent standard deviation of normalized modulus $\left(G / G_{\max }\right)$ and material damping $(\xi)$ (modified from Darendeli, 2001).

derived for generic clay sites by Darendeli (2001), which is the most comprehensive soil property dataset available.

3. The value of $G / G_{\max }$ at $0.03 \%$ strain as the representative property of nonlinear soil response for each layer. Successively, we use the perfect correlation between $G / G_{\max }$ values at different strains assumed in (1) to estimate the remaining $G / G_{\max }$ curve, and the perfect cor- relation between $G / G_{\max }$ and material damping $(\xi)$ described by (2) to generate the damping $(\xi)$ curve.

The autocorrelation function used in the Low-Strain Shear-Wave Velocity $\left(V_{S}\right)$ section to describe the $V_{S}$ spatial variability was also implemented here to describe the spatial variability of nonlinear properties. Based on available geotechnical data at the La Cienega downhole array site, we estimated a site-specific autocorrelation coefficient equal to 0.15 for the dynamic soil properties. Note that the corresponding coefficient for low-strain properties is estimated equal to 0.577 .

The two autocorrelation functions of linear and nonlinear layered soil profiles are compared in Figure 3, and it can be readily seen that the nonlinear dynamic soil properties between adjacent layers are much more weakly correlated than the $V_{S}$ values. This weak correlation between nonlinear soil properties of adjacent soil layers implies that the MCSs) of nonlinear parameters will require a larger number of profile realizations than the corresponding $V_{S}$ profiles, as shown in the following section. Finally, due to lack of additional geotechnical information, we implemented an autocorrelation coefficient equal to 0.15 for all three arrays studied. An example of $G / G_{\max }$ and material damping $(\xi)$ realizations at depth $7.5 \mathrm{~m}$ of the La Cienega downhole array are shown in Figure 8. In accordance to the $V_{S}$ stochastic model described in the Low-Strain Shear-Wave Velocity $\left(V_{S}\right)$ section, we implemented a 2-std truncation to the probability distribution function prior to generating random fields to avoid unrealistic physical bounds for the soil profiles.

\section{Random Field Realizations of Nonlinear}

\section{Soil Parameters}

To evaluate random realizations of the correlated $G / G_{\max }$ and material damping $(\xi)$ stochastic fields, we developed a new hysteretic scheme based on the model proposed by Muravskii (2005), which is capable of simultaneously matching
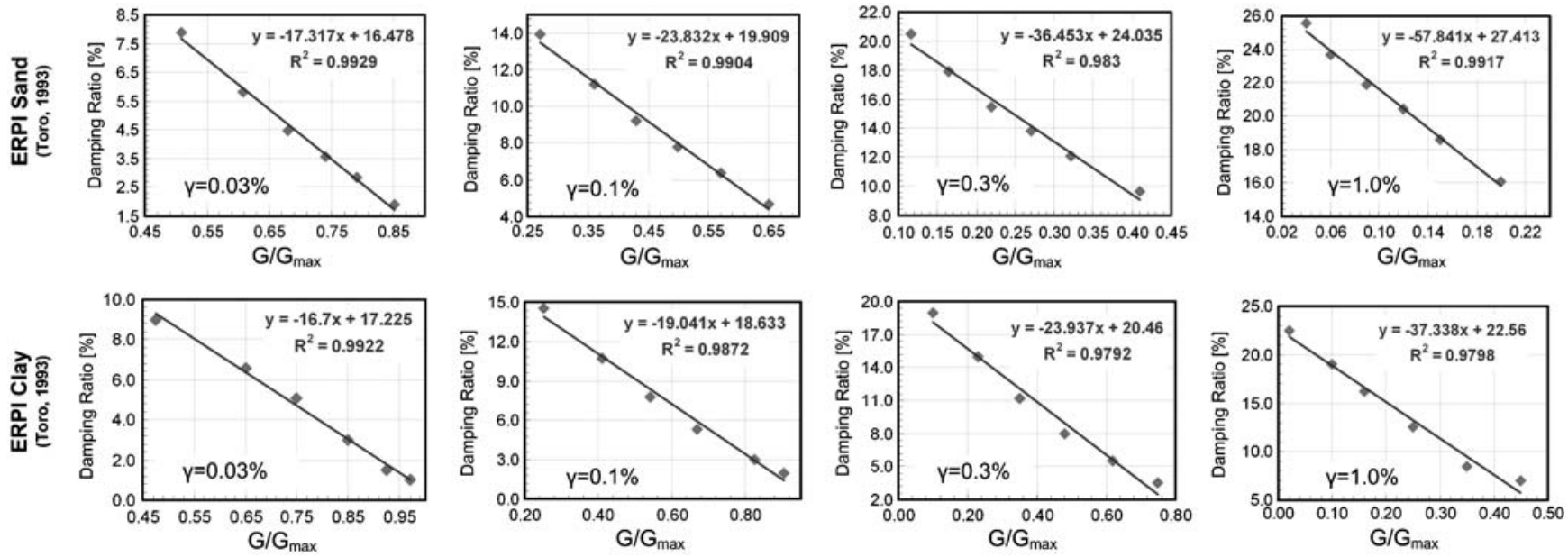

Figure 6. Correlation between normalized modulus $\left(G / G_{\max }\right)$ and material damping $(\xi)$ at multiple levels of strain amplitude $(\gamma)$ for the EPRI sand and EPRI clay database (Toro, 1993). 


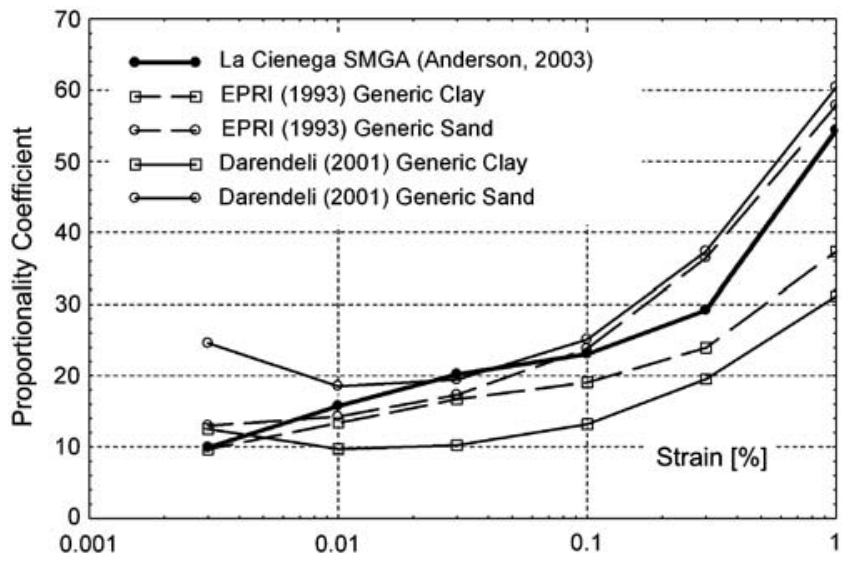

Figure 7. Proportionality coefficients between normalized modulus $\left(G / G_{\max }\right)$ and material damping $(\xi)$ as a function of strain, evaluated using generic soil properties from the EPRI (1993) and the Darendeli (2001) databases and site-specific geotechnical information at La Cienega SMGA (see also Fig. 6).

the $G / G_{\max }$ and material damping $(\xi)$ curves of soils in the intermediate to high strain range $\left(\gamma>10^{-3}\right)$. By contrast to the widely employed extended Masing rules (Pyke, 1979; Kramer, 1996) where the unload-reload branches of the hysteretic loop are scaled and reversed replicas of the monotonic (backbone) loading curve; the backbone curve and hysteretic functions of the new model are described by the same constitutive law yet different sets of parameters. Therefore, matching of the $G / G_{\max }$ curve is achieved by calibration of the monotonic curve parameters, separately from the matching of material damping $(\xi)$ curves that is achieved by calibration of the unload-reload parameters.

The new hysteretic scheme requires calibration of the hysteretic function parameters once and scaling of the backbone curve at stress reversals thereafter, by contrast to the original formulation by Muravskii (2005) that involves reevaluation of the unload-reload model parameters at every stress reversal point. An additional feature of the new hysteretic model is that the stiffness upon unloading may be less than the initial modulus at large shear strains, which is consistent with the material degradation of soils observed in the laboratory by Darendeli (2001). An example of the new hysteretic model response is shown in Figure 9, where a soil element with the nonlinear dynamic properties shown in Figure 8 is subjected to a transient excitation. The hysteretic loops predicted using the extended Masing rules (Kramer, 1996) are compared to the new hysteretic scheme: the narrower loops of the new model imply lower, more realistic material damping values at the corresponding shear strain amplitudes. For more information, the reader is referred to Assimaki et al. (2010).

\section{Monte Carlo Simulations for Uncertainty Propagation}

Among the three classes of methods widely used for studies of uncertainty propagation problems, namely, the ex-
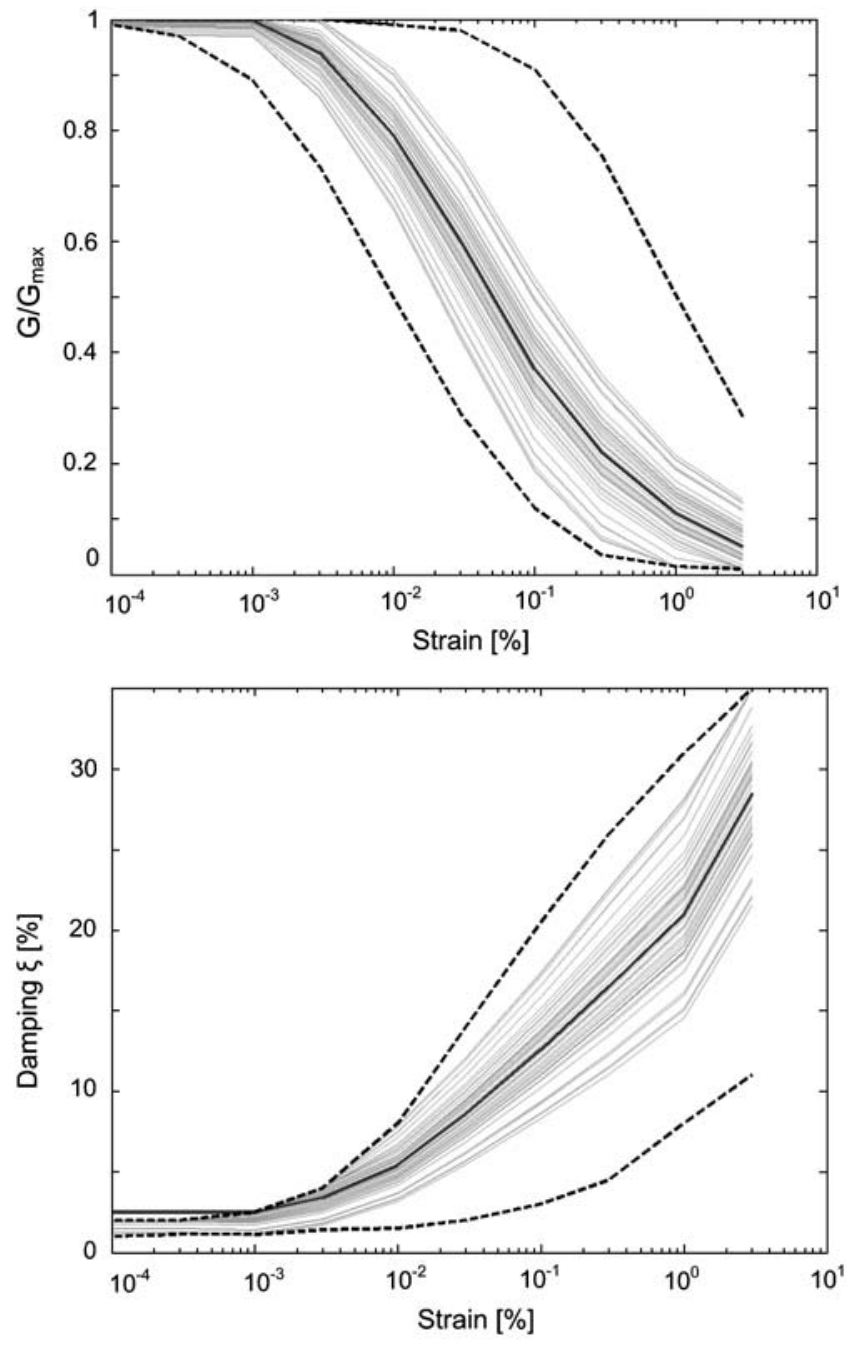

Figure 8. Sample realizations of normalized modulus $\left(G / G_{\max }\right)$ and material damping $(\xi)$ curves. The solid black lines correspond to the dynamic soil properties evaluated at the La Cienega SMGA at depth $7.5 \mathrm{~m}$ by Anderson (2003); the gray lines correspond to sample realizations of the probability model, and the dashed black lines correspond to the physical upper and lower bounds of dynamic soil behavior as estimated by Toro (1993) for the ensemble of soil samples in the EPRI database.

pansion-based, the point estimation, and the simulation-based methods, we implemented MCSs to evaluate the effects of soil parameter uncertainty on the ground response variability.

Despite the computational effort associated with MCSs, (1) the number of simulations to convergence is independent of the complexity of the propagation function, namely, the strong nonlinearity of this system would only affect the computational time of each analysis; (2) the correlation between soil parameters adopted in this work requires a relatively small number of simulations to convergence; and (3) MCS is the most robust uncertainty analysis technique that could be used here given the high soil parameter variability of the problem ( $\mathrm{COV} \approx 0.5$, as shown subsequently).

For the MCSs, we first conduct deterministic ground response analyses for each profile and the ensemble of ground 

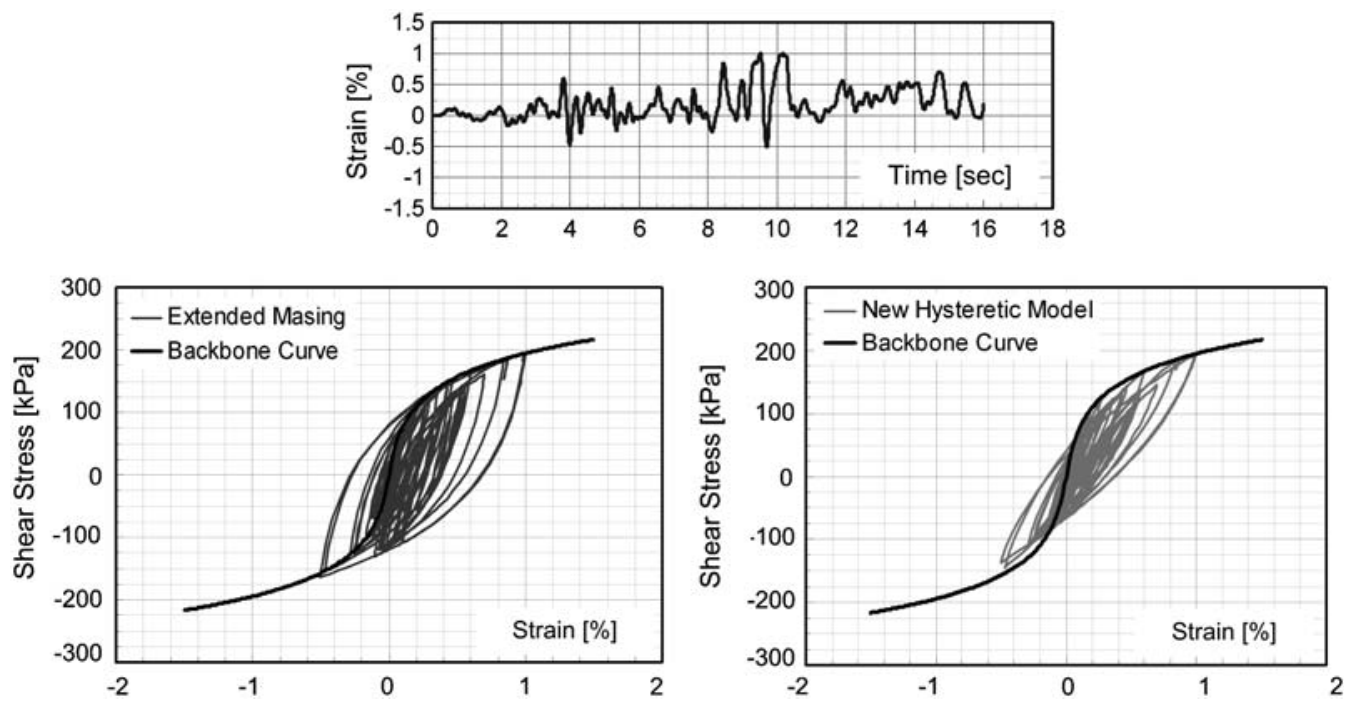

Figure 9. Nonlinear soil element subjected to transient strain time history (top). Comparison of backbone curve from modified Kondner and Zelasko (MKZ) model and hysteretic loops evaluated by means of the extended Masing rules (bottom, left) and backbone curve from MKZ model and hysteretic loops from the new hysteretic scheme developed based on Muravskii (2005) (bottom, right).

motions by simultaneously varying all free soil parameters $\left(V_{S}, G / G_{\max }\right.$, and $\left.\xi\right)$ and estimate the total variability introduced in ground response predictions due to the soil property randomness. Successively, we fix each of the free soil parameters, regenerate random profiles, and repeat the siteresponse simulations for all ground motions to estimate the reduction in ground-motion variability corresponding to fixing each parameter. Finally, we express the scatter in site response due to soil parameter uncertainty as a function of the ground-motion intensity and frequency content. The latter is evaluated in terms of the standard deviation of the logarithmic spectral acceleration (SA) of the response on ground surface $\left(\sigma_{\operatorname{lnSA}}\right)$.

It is instructive at this point to describe the convergence of MCSs for the base profile of the La Cienega site and two ground motions, a near-field strong motion anticipated to trigger significant nonlinear effects in the near surface, and a far-field weak motion expected to yield almost linear elastic site response. Figure 10 depicts the ground response variability for the first case, a near-field motion with peak ground acceleration (PGA) equal to $1.142 g$. The SAs evaluated from simultaneously randomizing the $V_{S}, G / G_{\max }$, and material damping $(\xi)$ profiles are shown in Figure 10b, while the SAs computed for random realizations of the $V_{S}$ and $G / G_{\max }$ stochastic models separately are shown in Figure 10c and d, respectively. As expected, the ground-motion SA variability is very large and is attributed both to the low-strain and the nonlinear soil parameter randomness.

Next, Figure 10e-g depicts the normal distribution of SA values at three different periods for the simulations shown in Figure 10b-d. As can be seen in all cases, the $\ln (\mathrm{SA})$ distribution at arbitrary periods is approximately normal, with the exception of a small deviation at the tails of the distribution. This result verifies that the strong motion ground response variability may be successfully evaluated by means of $\sigma_{\operatorname{lnSA}}$.

The evolution of $\sigma_{\ln S A}$ with number of realizations for this example is shown in Figure 11a-c. As expected, the strong correlation between $V_{S}$ values in adjacent layers (Low-Strain Shear-Wave Velocity $\left[V_{S}\right]$ section) yields fast convergence (i.e., less than 30 realizations) of the MCSs. By contrast, more than 50 realizations are required for convergence of the randomized $G / G_{\max }$ profile due to the very weak correlation of dynamic soil properties between adjacent layers (see the Modulus Reduction $\left[G / G_{\max }\right]$ and Material Damping $[\xi]$ section). The converged $\sigma_{\ln S A}$ spectral values of Figure 11a-c are compared in Figure 11d, where it can be seen that (1) the ground-motion variability for $T>3.5 \mathrm{sec}$ is relatively low $\left(\sigma_{\operatorname{lnSA}} \approx 0.2\right)$ and independent of which random fields are randomized; (2) for $T<1.5 \mathrm{sec}$, uncertainties in the dynamic soil response $\left(G / G_{\max }\right)$ are the primary source in the total system variability; and (3) for $1.5<T<3.5 \mathrm{sec}$, the low-strain and nonlinear soil properties contribute equally to the total ground-motion variability.

The MCS convergence for the weak-motion event $(\mathrm{PGA}=0.083 g)$ is illustrated in Figures 12 and 13, and as can be seen in Figure 12e-g, the ground response variability at any period may also be described by a lognormal distribution. At convergence (Fig. 13) the total ground response variability is almost exclusively attributed to uncertainties in $V_{S}$ due to the low intensity ground motion that does not trigger nonlinear effects.

\section{Comparison with Previous Studies}

Stewart and Kwok (2008) evaluated the ground-motion variability at the La Cienega downhole array for an $M_{\mathrm{w}} 4.2$ event that occurred on 9 September 2001 at distance $2.7 \mathrm{~km}$ from the site and was recorded by the downhole and surface 
(a)

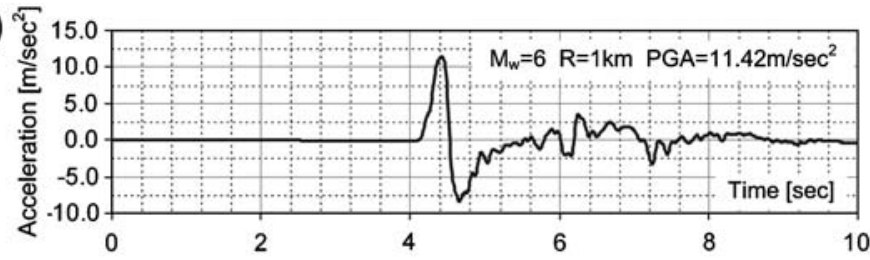

(b)

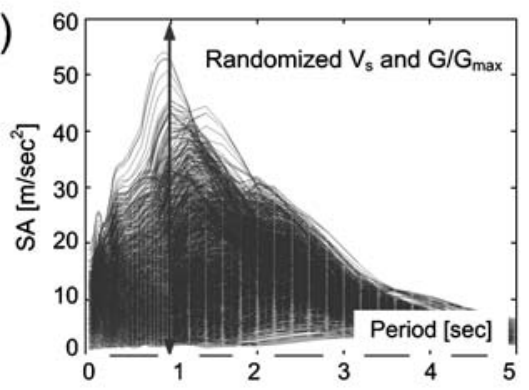

(e)

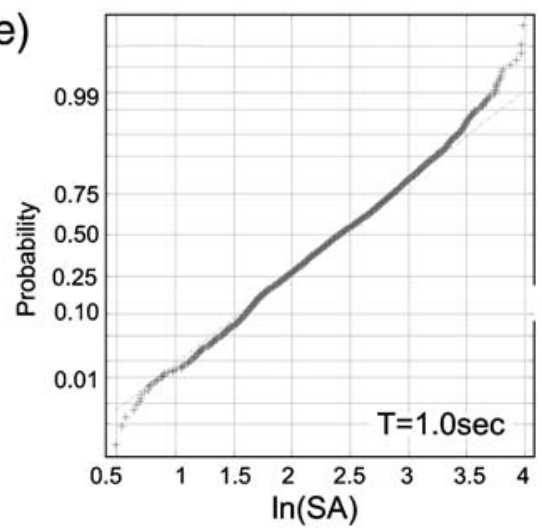

(c)

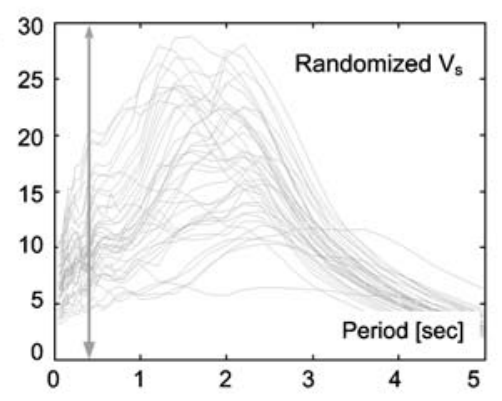

(f)

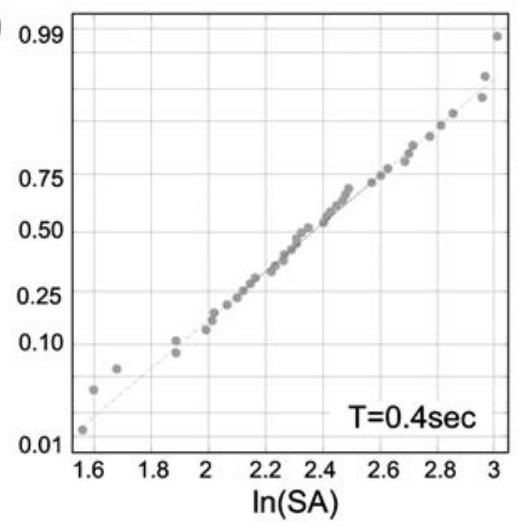

(d)

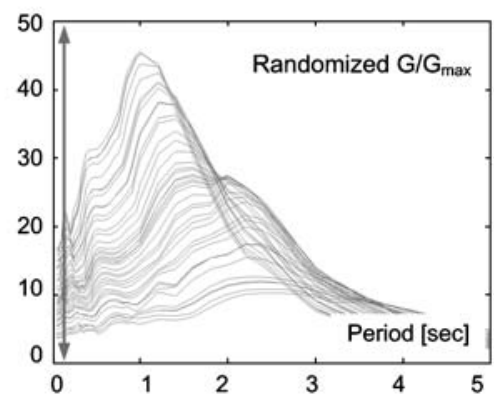

(g)

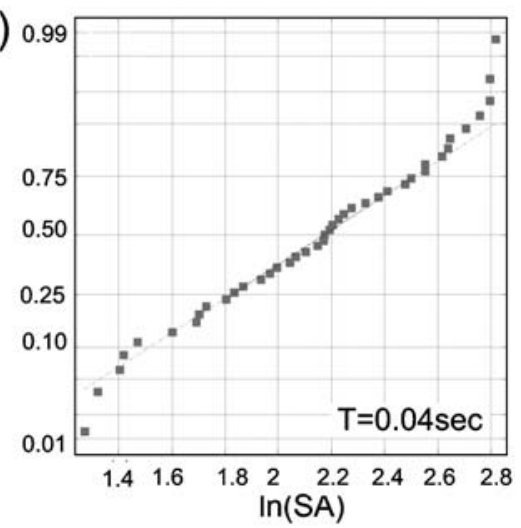

Figure 10. Variability in SA caused by uncertainties in soil parameters for a strong seismic excitation. (a) Rock-outcrop acceleration time history; (b) SA variability caused by $V_{S}$ and $G / G_{\max }$ randomness; (c) SA variability caused by $V_{S}$ randomness; (d) SA variability caused by $G / G_{\max }$ randomness; (e) normal plot of SA in (b) at period $T=1.0 \mathrm{sec}$; (f) normal plot of SA in (c) at period $T=0.4 \mathrm{sec}$; (g) normal plot of SA in (d) at period $T=0.04 \mathrm{sec}$.

instruments. Using the nonlinear model and statistical description of soil properties described previously, and the downhole recorded ground motion from Stewart and Kwok (2008), we first compute the surface ground motion and compare it to the recorded seismogram; as can be seen in Figure 14, results were found to be in excellent agreement with the observations. The second mode manifesting in the amplification function for some of the random velocity realizations is attributed to a strong velocity impedance contrast at $30 \mathrm{~m}$, whose amplitude is very sensitive to small fluctuations of the velocity profile at that depth.

Next, we estimate the ground-motion variability for this event (expressed in terms of $\sigma_{\ln S A}$ ) and compare our results to Stewart and Kwok (2008). Figure 15 shows that the values of $\sigma_{\ln \text { SA }}$ deviate substantially for $T<0.1 \mathrm{sec}$, attributed to differences in the statistical description of soil properties and in the uncertainty propagation methodology employed. More specifically, we use an autocorrelation function to describe the correlation structure between low-strain and nonlinear properties of adjacent layers, while Stewart and Kwok (2008) did implement no interlayer correlation. Also, Stewart and Kwok (2008) evaluated the uncertainty propagation using a FOSM method, as opposed to the MCS we employ; note, however, that FOSM is less suitable for problems with high $\mathrm{COV}$ such as the soil parameter uncertainty studied here. This comparison highlights the role of statistical model selection and uncertainty propagation methodology in estimating the ground response variability due to soil parameter uncertainty. Nonetheless, both studies identify the same trend of variability as a function of period, that is, the $G / G_{\max }$ variability dominates the low period uncertainty, while the effects of $V_{S}$ uncertainty manifest in the long-period region of ground response.

Finally, Figure 16 compares the ground-motion variability estimated in this study at the La Cienega downhole array for the strong-motion example, described in the Monte Carlo Simulations for Uncertainty Propagation section, to results from Roblee et al. (1996), Bazzuro and Cornell (2004), and the ground-motion variability for the attenuation relation by Boore and Atkinson (2008) for a similar site and event as 
(a)

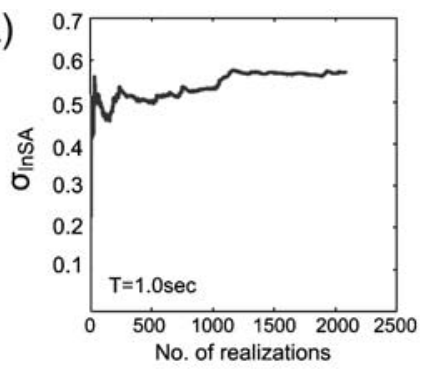

(b)

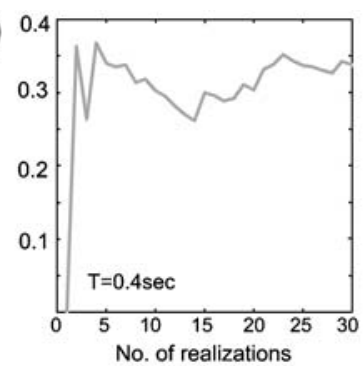

(c)

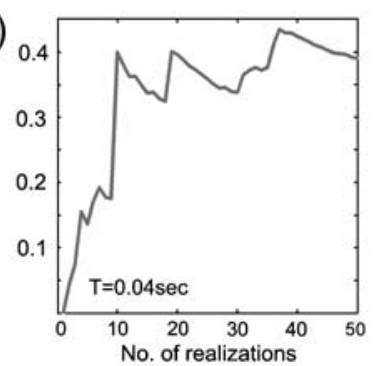

(d)

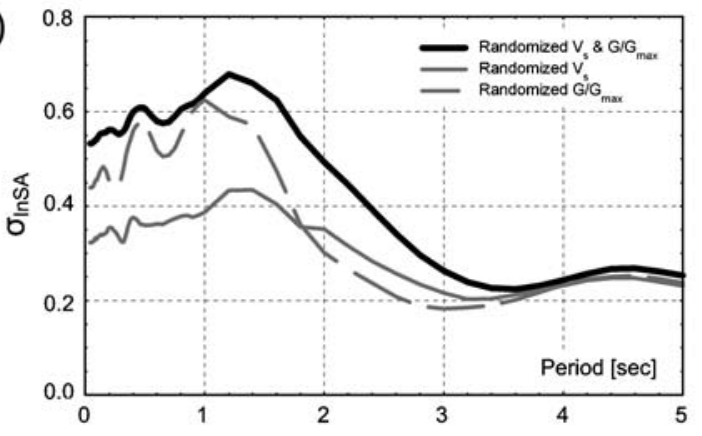

Figure 11. Convergence of $\ln (\mathrm{SA})$ with increasing number of realizations of soil properties for strong ground motion excitation: (a) SA variability caused by $V_{S}$ and $G / G_{\max }$ randomness; (b) SA variability caused by $V_{S}$ randomness; and (c) SA variability caused by $G / G_{\max }$ randomness. (d) Comparison of $\sigma_{\ln S A}$ at convergence caused by different combinations of randomized soil properties for a strong-motion excitation: the thick black line corresponds to combined uncertainties in $V_{S}$ and $G / G_{\max }$, and the solid and dashed gray lines correspond to uncertainties in $V_{S}$ or $G / G_{\max }$, correspondingly.

the one used in this study (i.e., $V_{S 30}=270 \mathrm{~m} / \mathrm{sec}, M 6.5$, and $R=10 \mathrm{~km}$ ). While the ground-motion variability estimates in Figure 16 are evaluated for different scenario earthquakes (real or synthetic) and are thus not perfectly applicable for comparison, we may still draw the following general conclusions. First, the ground-motion variability due to soil parameter uncertainty decreases for $T>1.0 \mathrm{sec}$ because the seismic wavelengths in the long-period range are longer than the thickness of soft soil layers in the near surface; for $T>1.0 \mathrm{sec}$, the primary source of total groundmotion variability as estimated by Roblee et al. (1996) and Boore and Atkinson (2008) is the uncertainty in the description of source and path. Nonetheless, the effects of parametric variability are shown to be sensitive to the nonlinear model used in site response, the statistical description of soil properties, the methodology used for uncertainty propagation, as well as the ground-motion characteristics (intensity and frequency content). As an example, the variability associated with parameter uncertainty decreases for $T>0.2 \mathrm{sec}$ in Roblee et al. (1996), for $T>0.5 \mathrm{sec}$ in Bazzuro and Cornell (2004), and for $T>1.0 \mathrm{sec}$ in this study.

Overall, results in Figures 11d, 13, 15, and 16 show that the role of soil parameter uncertainty in the total groundmotion variability is a function of the ground-motion intensity, both in terms of the amount of scatter $\left(\max \sigma_{\ln S A}=0.6\right.$ for the strong-motion example and $\max \sigma_{\operatorname{lnSA}}=0.3$ for the weak-motion example) and in terms of relative contribution of low-strain and nonlinear soil property uncertainties at different period ranges. The period range of parametric uncer- tainty influence is also strongly related to the site-specific conditions; for example, softer sites exert nonlinearities at lower intensity incident motions, and their response variability is anticipated to manifest at longer periods due to their resonant characteristics. In summary, the period range and extent to which the various soil parameter uncertainties dominate the total ground-motion variability are site and groundmotion specific. This outcome will be used in the following section, where we present results of the MCSs for the ensemble of ground motions and all three sites investigated.

\section{Site and Ground-Motion Dependent Ground Response Variability}

We finally illustrate the effects of soil parameter uncertainty on ground-motion variability for each site and the ensemble of synthetic ground motions and depict the dependency of ground-motion scatter on the site conditions and ground-motion intensity and frequency content. We use $\sigma_{\ln \mathrm{SA}}$ as measure of ground-motion variability, and more specifically compare

1. $\left(\sigma_{\operatorname{lnSA}}\right)_{V_{S}}$ that corresponds to $\sigma_{\ln \mathrm{SA}}$ evaluated for realizations of the $V_{S}$ probability model described in the LowStrain Shear-Wave Velocity $\left(V_{S}\right)$ section, and

2. $\left(\sigma_{\ln S A}\right)_{G / G_{\max }}$ that corresponds to $\sigma_{\ln S A}$ evaluated for realizations of the $G / G_{\max }$ and damping $(\xi)$ probability model described in the Modulus Reduction $\left(G / G_{\max }\right)$ and Material Damping $(\xi)$ section. 
(a)

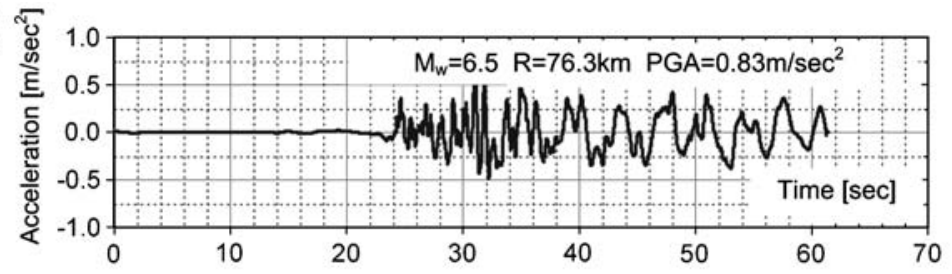

(b)

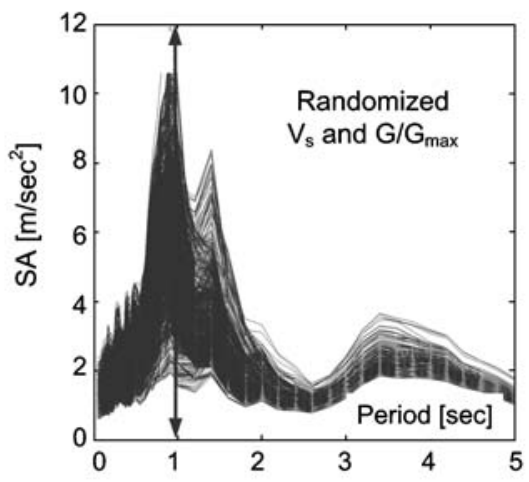

(e)

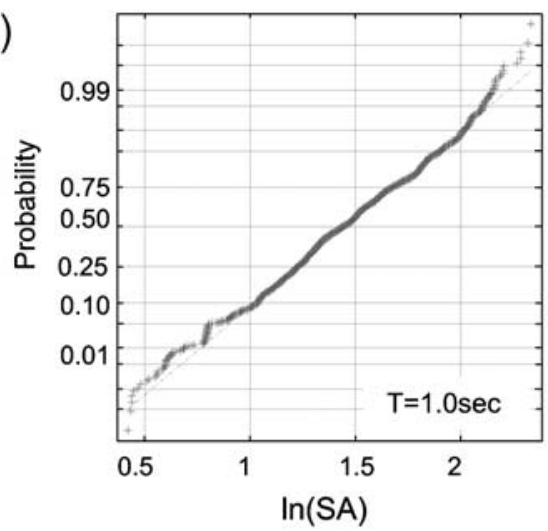

(c)

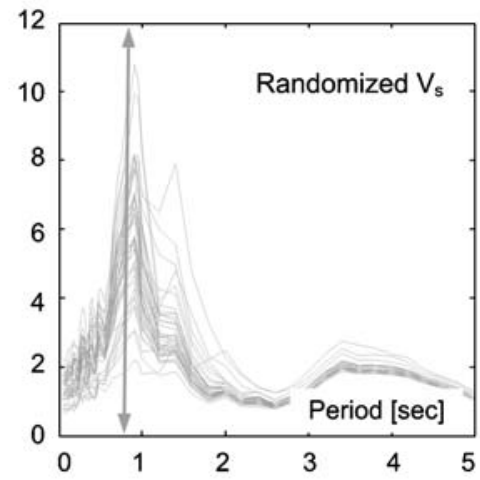

(f) 0

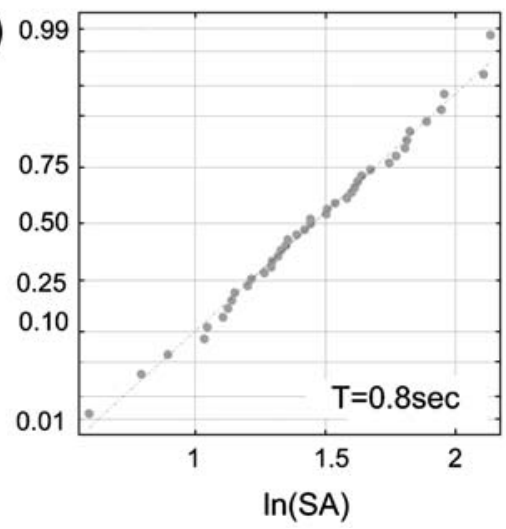

(d)

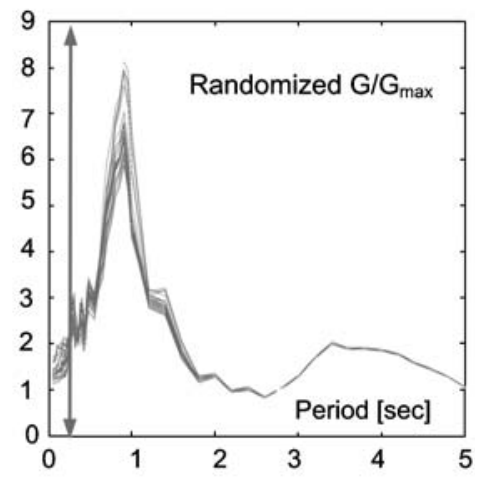

(g)

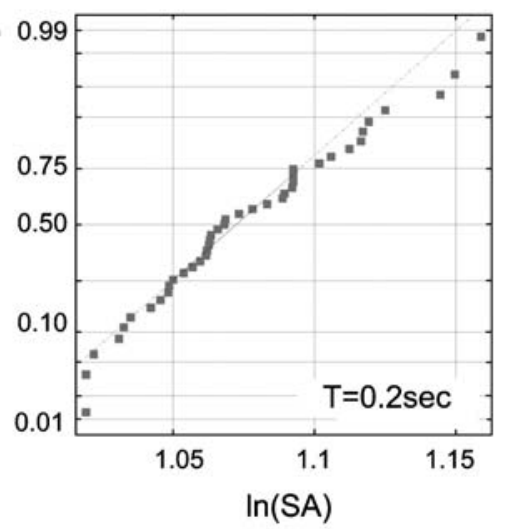

Figure 12. Variability in SA caused by uncertainties in soil parameters for a weak seismic excitation. (a) Rock-outcrop acceleration time history; (b) SA variability caused by $V_{S}$ and $G / G_{\max }$ randomness; (c) SA variability caused by $V_{S}$ randomness; (d) SA variability caused by $G / G_{\max }$ randomness; (e) normal plot of SA in (b) at period $T=1.0 \mathrm{sec}$; (f) normal plot of SA in (c) at period $T=0.8 \mathrm{sec}$; (g) normal plot of SA in (d) at period $T=0.2 \mathrm{sec}$.

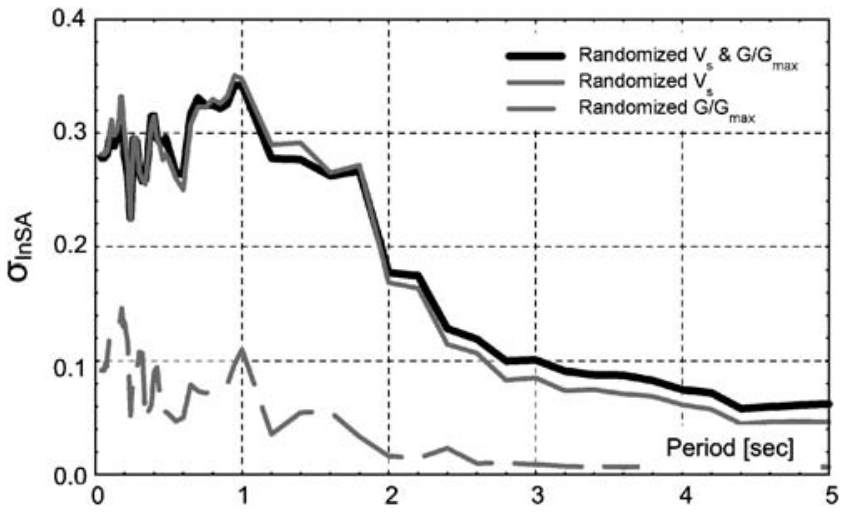

Figure 13. Comparison of $\sigma_{\ln S A}$ at convergence caused by different combinations of randomized soil properties for a weak-motion excitation: the thick black line corresponds to combined uncertainties in $V_{S}$ and $G / G_{\max }$, and the solid and dashed gray lines correspond to uncertainties in $V_{S}$ or $G / G_{\max }$, correspondingly.
Figure 17 shows contours of $\left(\sigma_{\ln S A}\right)_{V_{S}}$ and $\left(\sigma_{\ln S A}\right)_{G / G_{\max }}$ as a function of period $(T)$ and ground-motion PGA for each site and illustrates the intensity-frequency dependency of the effects of linear and nonlinear soil parameter uncertainty on ground-motion variability. For the stiffer sites (Obregon Park and La Cienega), the period range of maximum variability increases with increasing PGA, reaching an overall maximum at approximately $T=1.5 \mathrm{sec}$. This is attributed to characteristics of typical seismograms, where higher intensity motions are usually recorded in the near field and are thus rich in longperiod components. This trend is not as clear for the softer site (Meloland), most likely due to the particularities of the velocity profile that varies smoothly with depth and does not provide distinct resonance potential at any frequency range.

As expected, the effects of nonlinear soil property variability are more pronounced for soft sites (Fig. 17e and f), with the maximum $\left(\sigma_{\ln S A}\right)_{G / G_{\max }}$ being clearly a function of the site stiffness; on the other hand, the frequency dependency of 

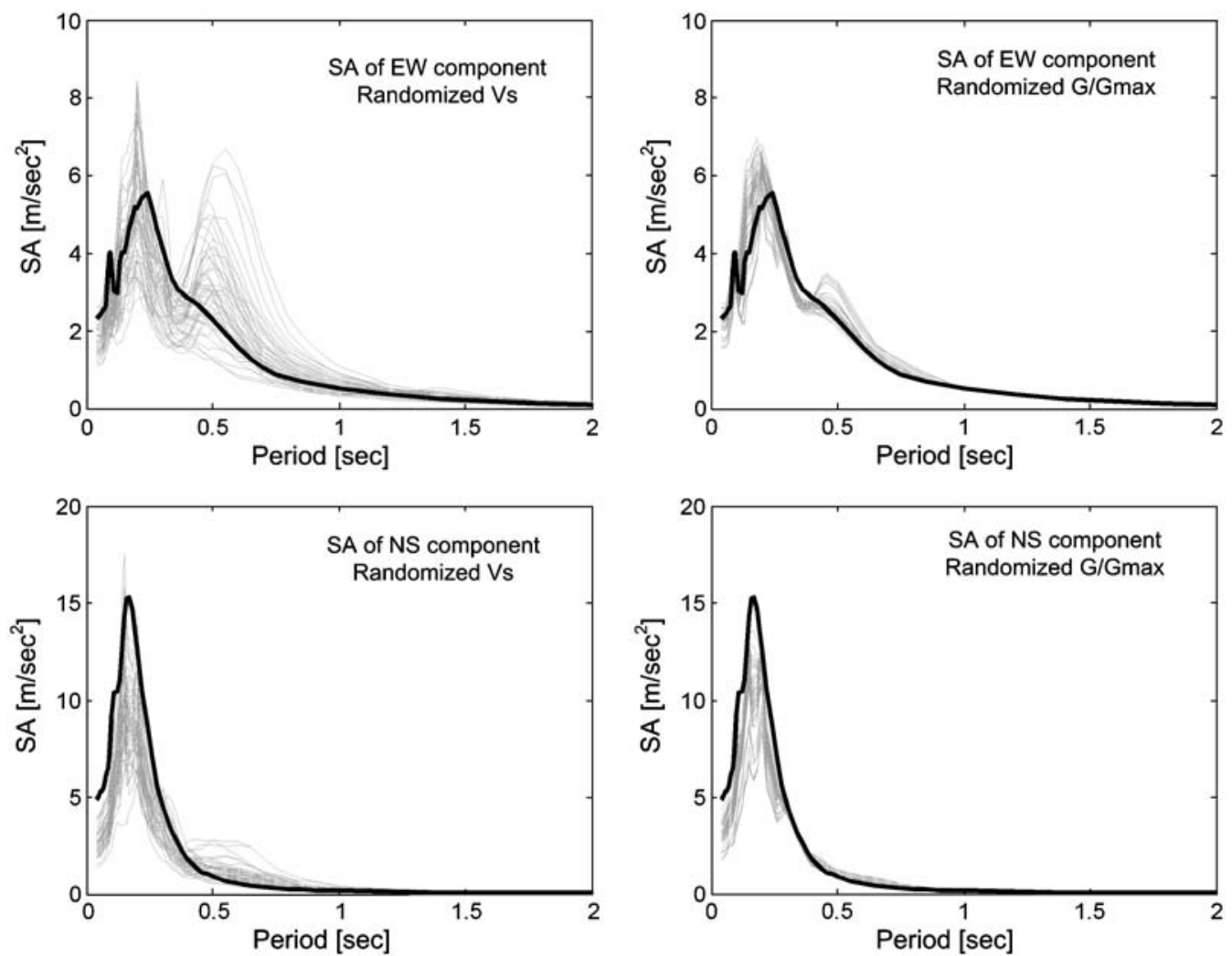

Figure 14. Comparison between ground surface predictions using randomized soil properties and observations for La Cienega downhole array site during an $M_{\mathrm{w}} 4.2$ event at distance $R=2.7 \mathrm{~km}$; the thick dark line corresponds to the SA of ground-motion observations, and the gray lines are SA predictions using the statistical model for soil properties in this work.

$\left(\sigma_{\operatorname{lnSA}}\right)_{G / G_{\max }}$ is similar for all three sites. By contrast, the effects of $V_{S}$ randomness described by $\left(\sigma_{\ln S A}\right)_{V_{S}}$ are much more pronounced for Obregon Park, which is the stiffer site studied (Fig. 17a). This is attributed to the strong velocity impedance contrast of the profile at $20 \mathrm{~m}$, which controls

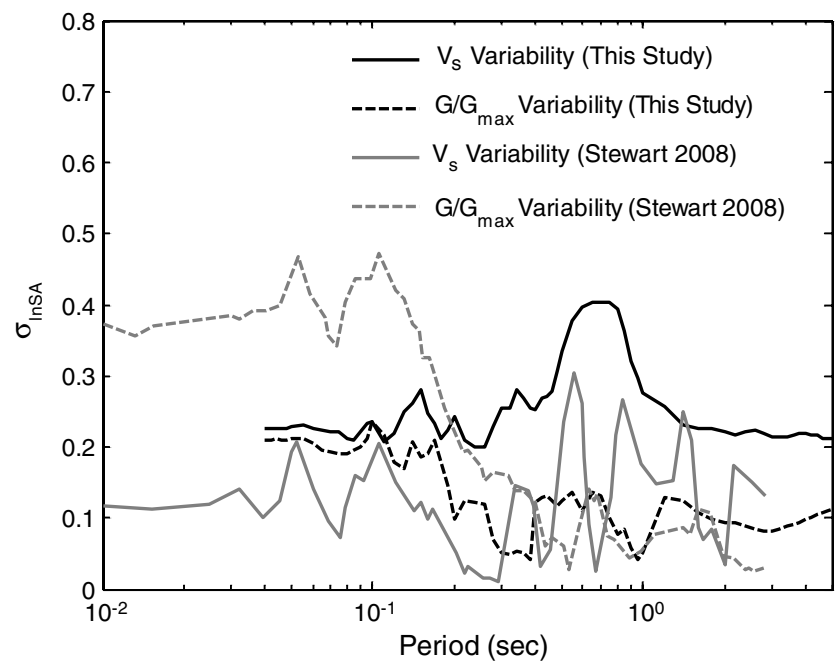

Figure 15. Comparison of the effects of soil parameter variability evaluated for the La Cienega downhole array site during an $M_{\mathrm{w}} 4.2$ event at distance $R=2.7 \mathrm{~km}$ and results obtained by Stewart et al. (2008).

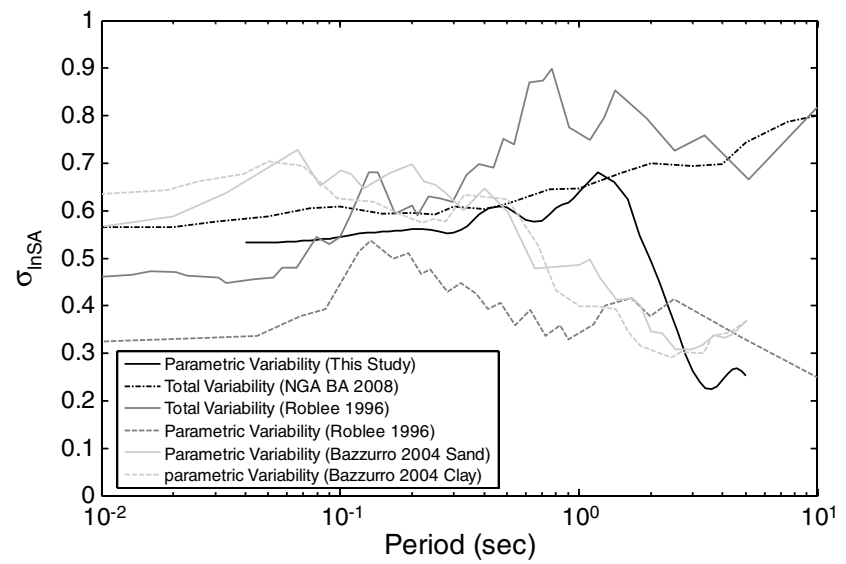

Figure 16. Comparison of ground-motion variability from site, path, and source-related uncertainties estimated by various studies: the soil parameter variability in this study is estimated for $\mathrm{La}$ Cienega during an $M 6$ event at distance $1 \mathrm{~km}$ (see key, this study); the total variability by Boore and Atkinson (2008) corresponds to a site with $V_{S 30}=270 \mathrm{~m} / \mathrm{sec}$ and an $M 6.5$ event at distance $R^{\mathrm{jb}}=$ $10 \mathrm{~km}$ (NGA BA 2008); the parametric variability by Roblee et al. (1996) is for a stiff site and an $M 7$ event at distance $10 \mathrm{~km}$ (Roblee 1996); and the parameter uncertainty by Bazzurro and Cornell (2004) is for generic sand and clay sites (Bazzurro 2004 Sand and Bazurro 2004 Clay), and the variability shown is for site amplification instead of ground motion. 

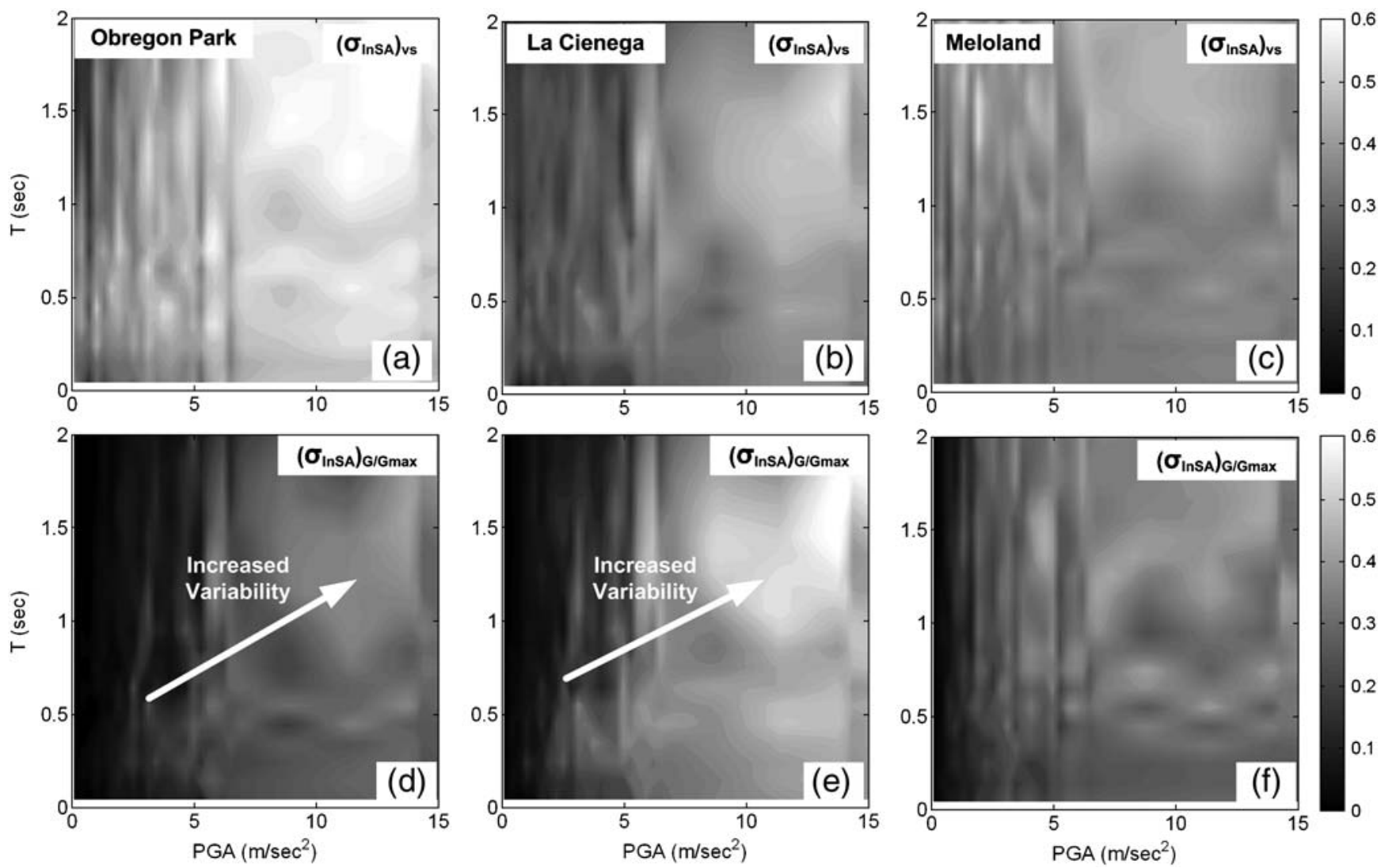

Figure 17. Contour map of SA variability due to $V_{S}$ randomness (evaluated via $\left(\sigma_{\ln S A}\right)_{V_{S}}$ ) and SA variability due to $G / G_{\max }$ randomness (evaluated via $\left.\left(\sigma_{\ln S A}\right)_{G / G \max }\right)$ as a function of the reference site PGA $\left(\mathrm{PGA}_{\mathrm{RO}}\right)$ and period $(T)$ for the three sites investigated.

the amount of seismic energy trapped and amplified in the near-surface. Therefore, fluctuations of the velocity model for this site are expected to directly reflect on changes in the surface ground motion, and this sensitivity is reflected in the ground-motion variability.

\section{Conclusions}

We have presented a systematic investigation of the ground-motion variability in site-response predictions arising from uncertainties in the soil parameters. More specifically, we studied three soil profiles corresponding to downhole array sites in the LA basin, for which we developed realistic probability models for the linear elastic and nonlinear soil properties based on site-specific and generic geotechnical data. Based on these models, we developed randomized realizations of the soil property stochastic fields and subjected each to broadband ground-motion synthetics from simulations of a wide range of magnitude-distance scenarios. We then implemented MCSs to evaluate the uncertainty propagation from the soil parameters to the ground surface response and presented the ground-motion variability results for each site as a function of the ground-motion intensity (here represented by the rock-outcrop peak ground acceleration $\mathrm{PGA}_{\mathrm{RO}}$ ) and frequency.
In contrast to previously published studies, we simultaneously implement a fully nonlinear soil model in the siteresponse simulations, realistic statistical descriptions of the soil properties and conduct MCSs for approximately 500 incident ground-motion time-histories and three sites to evaluate the intensity-frequency dependency of soil parameter uncertainty in ground-motion variability. Results show strong dependency of the effects of nonlinear soil property uncertainties $\left(G / G_{\max }\right)$ to the seismic motion intensity, which was shown to be stronger for soft soil profiles. In contrast, ground-motion variability associated with uncertainties in the velocity structure of soil profiles $\left(V_{S}\right)$ is shown to be less intensity dependent and more sensitive to the existence of velocity profile discontinuities in the near surface that govern the amplification potential of the site.

Results of this study, however, were obtained for a small number of soil profiles, which are not statistically significant in number to allow general conclusions to be drawn. We are currently investigating a larger number of soil profiles, with the objective being to develop a set of quantitative criteria and to describe which are the dominant sources of groundmotion variability in site-response analyses, namely, soil model, velocity profile, or nonlinear properties, as a function of the site conditions and ground-motion intensity and frequency content. 


\section{Data and Resources}

All data used in this article came from published sources listed in the references. For information about the 3D Southern California Community Velocity Model IV, see http://www .data.scec.org/3Dvelocity/.

\section{Acknowledgments}

This research was supported by the Southern California Earthquake Center (SCEC). SCEC is funded by National Science Foundation (NSF) Cooperative Agreement EAR-0106924 and U.S. Geological Survey (USGS) Cooperative Agreement 02HQAG0008. The SCEC contribution number for this article is 1259 . The authors would also like to thank the three anonymous reviewers of this manuscript; their comments were very helpful in revising the article to its final form.

\section{References}

Anderson, D. G. (2003). Laboratory testing of nonlinear soil properties: I \& II, Lifelines Research Program, Pacific Earthquake Engineering Research Center, University of California at Berkeley.

Andrade, J. E., and R. I. Borja (2006). Quantifying sensitivity of local site response models to statistical variations in soil properties, Acta Geotec. $1,3-14$.

Assimaki, D., A. Kalos, and W. Li (2010). A wavelet-based seismogram inversion algorithm for the in-situ characterization of nonlinear soil behavior, Pure Appl. Geophys. (in press).

Assimaki, D., W. Li, J. M. Steidl, and J. Schmedes (2008). Quantifying nonlinearity susceptibility via site response modeling uncertainty at three sites in the Los Angeles Basin, Bull. Seismol. Soc. Am. 98, no. 5, 2364-2390.

Assimaki, D., A. Pecker, R. Popescu, and J. Prevost (2003). Effects of spatial variability of soil properties on surface ground motion, J. Earthquake Eng. 7, 1-44.

Assimaki, D., Steidl, J., Liu, and P.-C. (2006). Attenuation and velocity structure for site response analyses via downhole seismogram inversion, Pure Appl. Geophys. 163, 81-118.

Bazzurro, P., and C. A. Cornell (2004). Ground-motion amplification in nonlinear soil sites with uncertain properties, Bull. Seismol. Soc. Am. 94, no. 6, 2090-2109.

Benjamin, J., and C. A. Cornell (1971). Probability, Statistics, and Decisions for Civil Engineers, McGraw-Hill, New York.

Boore, D. M., and G. M. Atkinson (2008). Ground-motion prediction equations for the average horizontal component of PGA, PGV, and 5\%damped PSA at spectral periods between $0.01 \mathrm{~s}$ and $10.0 \mathrm{~s}$, Earthquake Spectra 24, no. 1, 99-138.

Borja, R. I., C.-H. Lin, K. M. Sama, and G. M. Masada (2000). Modelling non-linear ground response of non-liquefiable soils, Earthquake Eng. Struct. Dyn. 29, 63-83.

Darendeli, M. B. (2001). Development of a New Family of Normalized Modulus Reduction and Material Damping Curves, Department of Civil, Architectural and Environmental Engineering, The University of Texas, Austin, Texas.

Dham, S., and R. Ghanem (1995). Stochastic finite element analysis for multiphase flow in heterogeneous porous media, in Computational Stochastic Mechanics, P. D. Spanos (Editors), Balkema, Rotterdam, 429-434.

EPRI (1993). Guidelines for determining design basis ground motions, Electric Power Research Institute, Palo Alto, California.

Fenton, G. A. (1990). Simulation and Analysis of Random Fields, Princeton University, Princeton, New Jersey.

Fenton, G. A., and D. V. Griffiths (1996). Stochastics of free surface flow through stochastic earth dam, J. Geotech. Eng. 122, no. 6, $427-436$.
Fenton, G. A., and D. V. Griffiths (2001). Bearing capacity of spatially random $c-\varphi$ soils, Proc. of the 10th International Conf. Computer Methods and Advances in Geomechanics (IACMAG 01), Tucson, Arizona, 7-12 January 2001, 1411-1415.

Field, E. H., and K. H. Jacob (1993). Monte-Carlo simulation of the theoretical site response variability at Arkey Flat, California, given the uncertainty in the geotechnically derived input parameters, Earthquake Spectra 9, no. 4, 669-701.

Griffiths, D. V., and G. A. Fenton (1993). Seepage beneath water retaining structures founded on spatially random soil, Geotechnique 43, no. 4, 577-587.

Hashash, Y. M. A., D. R. Groholski, C. A. Phillips, and D. Park (2008). DEEPSOIL v3.5beta User Manual and Tutorial, University of Ilinois at Urbana-Champaign.

Hwang, H. H. M., and C. S. Lee (1991). Parametric study of site response analysis, Soil Dyn. Earthquake Eng. 10, no. 6, 282-290.

Idriss, I. M., and J. I. Sun (1992). User's Manual for Shake91, Center for Geotechnical Modeling, Department of Civil Engineering, University of California, Davis.

Kottke, A. R., and E. M. Rathje (2008). Technical Manual for Strata, Pacific Earthquake Engineering Research Center.

Kramer, S. L. (1996) Geotechnical Earthquake Engineering, Prentice-Hall, Upper Saddle River, New Jersey.

Kwok, A. O. L., J. P. Stewart, and Y. M. A. Hashash (2008). Nonlinear ground-response analysis of Turkey Flat shallow stiff-soil site to strong ground motion, Bull. Seismol. Soc. Am. 98, no. 1, 331-343.

Liu, P., R. J. Archuleta, and S. H. Hartzell (2006). Prediction of broadband ground-motion time histories: Hybrid low/high-frequency method with correlated random source parameters, Bull. Seismol. Soc. Am. 96, 2118-2130.

Matasovic, N., and V. Mladen (1995). Seismic response of soil deposits composed of fully-saturated clay and sand layers, in Earthquake Geotechnical Engineering, Balkema, Rotterdam.

Muravskii, G. (2005). On description of hysteretic behavior of materials, Int. J. Solids Struct. 42, 2625-2644.

Nobahar, A., and R. Popescu (2000). Spatial variability of soil propertieseffects on foundation design, Proc. of the 53rd Canadian Geotechnical Conference, Montreal, Quebec, 1139-1144.

Nour, A., A. Slimani, N. Laouami, and H. Afra (2003). Finite element model for the probabilistic seismic response of heterogeneous soil profile, Soil Dyn. Earthquake Eng. 23, 331-348.

Ohtomo, K., and M. Shinozuka (1990). Two-dimensional spatial severity of liquefaction, Proc. of the 8th Japan Earthquake Engineering Symposium, Tokyo.

Paice, G. M., D. V. Griffiths, and G. A. Fenton (1996). Finite element modeling of settlements on spatially random soil, J. Geotech. Eng. 122, no. 9, 777-779

Phoon, K.-K., and F. H. Kulhawy (1999). Characterization of geotechnical variability, Can. Geotech. J. 36, 612-624.

Popescu, R. (1995). Stochastic Variability of Soil Properties: Data Analysis, Digital Simulation, Effects on System Behavior, Princeton University, Princeton, New Jersey.

Popescu, R., J. H. Prevost, and E. H. Vanmarcke (1995). Numerical simulations of soil liquefaction using stochastic input parameters, Proc. of the 3rd International Conference on Recent Advances in Geotechnical Earthquake Engineering and Soil Dynamics, St. Louis, Missouri, 2-7 April 1995.

Pyke, R. (1979). Nonlinear soil model for irregular cyclic loading, J. Geotech. Eng. Div. 105, 715-726.

Rahman, M. S., and C. H. Yeh (1999). Variability of seismic response of soils using stochastic finite element method, Soil Dyn. Earthquake Eng. 18, 229-245.

Roblee, C. J., W. J. Silva, G. R. Toro, and N. A. Abrahamson (1996). Variability in site-specific seismic ground motion design predictions, in Uncertainty in the Geologic Environment: From Theory to Practice, C. D. Shakelford and P. P. Nelson (Editors), ASCE Geotech Special 
Publication No. 58, Proc. of Uncertainty, Madison Wisconsin, 31 July-3 August 1996.

Stewart, J. P., and A. O. Kwok (2008). Nonlinear seismic ground response analysis: Code usage protocols and verification against vertical array data, in Geotechnical Engineering and Soil Dynamics IV, D. Zeng, M. T. Manzari, and D. R. Hiltunen (Editors), ASCE Geotechnical Special Publication No. 181, Sacramento, California, 24 pp (electronic file).

Suzuki, S., and K. Asano (1992). Dynamic amplification functions of the surface layer considering the variation of soil parameters, in 10th World Conf. on Earthquake Engineering, Madrid, Spain, 19-24 July 1992.

Tian, L., and L. Jie (1992). Influence of random mechanical parameter on earthquake response analysis of site, 10th World Conf. on Earthquake Engineering, Madrid, Spain, 19-24 July 1992.

Toro, G. R. (1993). Probabilistic model of soil-profile variability, in Early Site Permit Demonstration Program: Guidelines for Determining Design Basis Ground Motions, J. F. Schneider (Editor), EPRI Project RP3302, Volume II, Appendix 6A, Electric Power Research Institute.
Ural, D. (1995). Effects of spatial variability of soil properties on liquefaction, Princeton University, Princeton, New Jersey.

Wang, S., and H. Hao (2002). Effects of random variations of soil properties on site amplification of seismic ground motions, Soil Dyn. Earthquake Eng. 22, 551-564.

Wu, Z., and G. Han (1992). Stochastic seismic response analysis for soil layers with random dynamic parameters, 10th World Conf. on Earthquake Engineering, Madrid, Spain, 19-24 July 1992.

School of Civil and Environmental Engineering Georgia Institute of Technology

Atlanta, Georgia

Manuscript received 3 February 2009 